\title{
MODELLING STORM SURGE WAVE OVERTOPPING OF SEAWALLS WITH NEGATIVE FREEBOARD
}

\author{
David K. Jones ${ }^{1}$, Qingping Zou ${ }^{2}$, Dominic E. Reeve ${ }^{3}$
}

A Reynolds-averaged Navier-Stokes based wave model (RANS) is used to simulate storm surge wave overtopping of embankments. The model uses a wave generating boundary condition that accepts a wave time history as an input and reproduces the time history in the model. This allows a direct wave by wave simulation of recorded data. To investigate the success of the model at reproducing the wave generation, transformation and overtopping processes the model is compared with experimental laboratory data. A wave-by-wave comparison is performed for overtopping parameters such as discharge, depth and velocity. Finally the overtopping discharge predicted by the model is compared against design formulae.

Keywords: overtopping, embankment, storm surge

\section{INTRODUCTION}

Coastal flooding is caused by combinations of high tides, waves, wind set-up and storm surges driven by low-pressure systems. With global warming causing sea levels to rise and the potential of increased storminess to cause more extreme waves and storm surges, the likelihood of overtopping may well be expected to increase.

Protection of low-lying areas of the world against coastal flooding is often in the form of armoured earthen embankments or levees and the determination of adequate height of these structures is key to their success at protecting coastal areas. In determining the crest elevation a balance must be met between the cost of increasing crest elevation against the consequences of overtopping or breach. The difference in the level between the defence crest and the undisturbed water depth is known as the freeboard.

During extreme storm events, embankments may experience situations where the freeboard is very small or even negative, leading to a combination of pure overflow (weir flow) and wave overtopping. At these times, as well as the obvious danger presented by the volume of water flowing over the crest there is also the potential for the overflow to remove lee side protection, erode the back face and possibly breach the embankment.

Overtopping of embankments can be caused by various situations. Overtopping occurs in the form of wave overtopping which is a result of large waves running up the front face of the structure that has positive freeboard, resulting in intermittent overtopping. High tides combined with low pressure surge levels can cause surge overflow with negative freeboard and little or no waves. Low pressure systems are often associated with storms, so possibly the worst situation for overtopping will be caused by low pressure storm surge causing over flow with negative freeboard combined with waves. It is this worst situation that is investigated in this paper.

In what follows, to avoid confusion, we use 'overtopping' to refer to wave overtopping a defence with positive freeboard, 'overflow' to refer to the flow of water over a crest (negative freeboard) in the absence of waves and 'combined discharge' to refer to the flow of water over the crest when waves are combined with negative freeboard conditions.

The crest elevation of embankments has historically been set by examination of local records or design formulae determined from physical models. For wave overtopping and run-up on embankments with positive freeboard the formulae for predicting wave-overtopping rates are usually based on empirical equations based on hydraulic model data. For wave overtopping there exists extensive model data, (eg. van der Meer 2009), against which to validate models and for surge overflow of a wide defence without waves the situation can be modelled as a broad crested weir. However, for combined discharge considerably less work has been conducted. Schuttrumpf (2001) developed equations for wave overtopping at zero freeboard based on experimental laboratory data. A method developed to evaluate combined discharge is to sum the wave component derived using the equation developed by Schuttrumpf along with the surge component calculated using weir equations. More recently overtopping discharge formulae have been derived that allows the combined discharge to be calculated directly. This work was conducted by Reeve et al. (2008) and was carried out in a numerical wave flume using a Reynolds-averaged Navier-Stokes based wave model and a Volume of Fluid surface capturing scheme (RANS-VOF). The formulae produced were tested

1 Britannia Royal Naval College, College Way, Dartmouth, Devon, UK. TQ6 OHJ

2 Coastal Engineering Research Group, University of Plymouth, Plymouth Devon PL4 8AA UK.

3 Coastal Engineering Research Group, University of Plymouth, Plymouth Devon PL4 8AA UK 
against the results predicted by Schuttrumpf combined with the weir equations. At that point no hydraulic physical model data existed for combined wave and storm surge overtopping. More recently still, Hughes and Nadal (2009) reported the results of a laboratory study of overtopping caused by combined wave and storm surge and produced design equations that predicted more modest overtopping than Reeve et al. (2008) had predicted.

This paper assesses the ability of a modified version of the RANS-VOF numerical model used by Reeve et al. (2008) to directly reproduce on a wave by wave basis the tests conducted by Hughes and Nadal (2009). This is achieved by using an alternative wave absorbing boundary condition that allows a wave time history as input but without the usual wave absorbing sponge layer required to allow the outgoing waves to leave the computational domain without reflection. The validated model is then used to determine combined discharge rates and the results are compared with design formulae and differences between design formulae are investigated.

\section{Empirical Formulae}

In this section some commonly used design formulae that are employed to estimate discharge rates for wave overtopping of embankments are presented. Schuttrumpf developed Equations (1) to determine overtopping discharge caused by waves overtopping at zero freeboard. These equations are based on model studies for uniform smooth slopes between 1:3 and 1:6. To estimate the combined discharge these equations are summed with the equation for flow over a broad crested weir, with the surge component being calculated with the weir equation and the wave component being calculated with Equation (1). Clearly this simple addition of the two components is a coarse approximation to reality and does not fully describe the complex hydrodynamic situation; it might however be expected to provide a reasonable first approximation to the problem.

$$
\begin{array}{ll}
\frac{q}{\sqrt{g \cdot H_{m 0}^{3}}}=0.0537 . \xi_{m-1,0} & \text { for } \xi_{m-1,0}<2.0 \text { Breaking waves } \\
\frac{q}{\sqrt{g \cdot H_{m 0}^{3}}}=0.136-\frac{0.226}{\xi_{m-1,0}^{3}} & \text { for } \xi_{m-1,0} \geq 2.0 \text { Non breaking waves }
\end{array}
$$

There are a number of different equations used to determine flow over broad crested weirs. Possibly the simplest equation for ideal flow is given in Chadwick and Morfett (1998) as:

$$
q=C_{d} \times 1.705 b h^{3 / 2}
$$

where $b$ is the weir breadth and $h$ is the upstream depth above the weir crest and $C_{d}$ is 1.0 for ideal fluids. For real fluids $C_{d}$ has been derived empirically by Ackers et al (1978). For $0.45<h / L<0.8$ and $0.35<h /\left(h+h_{1}\right)<0.6 C_{d}$ has been given by Chadwick \& Morfett (1998) as:

$$
C_{d}=0.848\left[0.91+0.21 \frac{h}{L}+0.24\left(\frac{h}{h+h_{1}}-0.35\right)\right]
$$

where $L$ is the length of the weir crest and $h_{1}$ is the water depth to the crest of the weir. Pullen et al. (2007) presented Equation (4) as a suitable formula for use with Equation (1) when determining combined wave and surge overtopping, where $-R_{c}$ is the overflow depth measured at the weir and $q$ is the discharge per metre length of defence. The key difference between Equation (4) and Equation (2) is the location the depth of flow is measured at. The flow depth recorded at the weir crest is subject to the draw down that occurs near broad crested weirs.

$$
q=0.6 \cdot \sqrt{g .\left|-R_{c}^{3}\right|}
$$

The equation for combined wave overtopping and storm surge developed by Reeve et al. are given in Equation (5). The equations are based on regression analysis of validated numerical flume tests for irregular breaking and non breaking waves on seawalls with slopes 1:3, 1:4 and 1:6 and small negative dimensionless freeboards in the region $0.0>R \geq-0.8$.

$$
\begin{array}{ll}
Q=\frac{q}{\sqrt{g \cdot H_{s}^{3}}} \cdot \frac{\sqrt{\tan \alpha}}{\xi_{p}}=0.051 \exp \left(-1.98 \frac{R_{c}}{H_{s} \xi_{p}}\right) & \text { for } \xi_{p}<2.0 \\
Q=\frac{q}{\sqrt{g \cdot H_{s}^{3}}}=0.233 \exp \left(-1.29 \frac{R_{c}}{H_{s}}\right) & \text { for } \xi_{p} \geq 2.0
\end{array}
$$


The laboratory experiments of combined wave and surge overtopping conducted by Hughes and Nadal (2009) allowed the following best-fit equation, Equation (6), to be developed. These tests were conducted for irregular breaking and non-breaking waves on a seawall slope of 1:4.25 and for negative freeboards, $R_{c}$ of $0.29,0.81$ and $1.3 \mathrm{~m}$, at a scale of $1: 25$.

$$
\frac{q}{\sqrt{g . H_{m 0}^{3}}}=0.034+0.53\left(\frac{-R_{c}}{H_{m 0}}\right)^{1.58} \quad \text { for } \mathrm{R}_{\mathrm{c}}<0
$$

It should be noted that although well-established this range of predictors for discharge indicates a degree of uncertainty. For example, relationships inferred from computer models will be influenced by the assumptions inherent in the numerical model, while relationships derived from laboratory experiments will be subject to experimental error, scaling effects and so on.

In this paper a comparison is made between the overtopping discharge calculated with the above formulae and that estimated with the RANS-VOF model.

\section{Numerical modelling}

The RANS-VOF model is used in this study to calculate the free surface and general turbulent flow. It has been coupled with a second-order $k-\varepsilon$ turbulence closure model, where $k$ is the turbulent kinetic energy and $\varepsilon$ is the turbulence dissipation. The model uses a set of equations for the mean flow containing contributions from the fluctuating turbulent flow. The RANS-VOF model uses the two step projection finite difference method (Chorin, 1968) to solve the Reynolds equations. The calculation of mean flow has been based on an earlier Navier-Stokes equation solver RIPPLE that was developed at Los Alamos Laboratory (Kothe et al., 1991). A fuller description of the model can be found in Lin \& Liu (1998).

The usual boundary conditions are applied within the model. That is, if the mesh is small enough to resolve the viscous boundary layer then the no slip boundary condition would be applied. However for these tests, to be computationally efficient, the mesh is not fine enough to resolve the boundary layer. If the viscous boundary layer is not resolved then a free-slip condition is more appropriate at a solid boundary. In this case the turbulent field near the solid boundary is described using the log-law to find the distribution of mean tangential velocities within the boundary layer. This allows values of $k$ and $\varepsilon$ to be expressed as a function of distance from the solid boundary.

The wave generation in the model uses a wave time history defined at the seaward boundary, as developed by Torres-Freyermuth (2007). This is sometimes used in preference to a source function, (eg Lin \& Liu 1999), because the absorbing sponge layer is not required at absorbing boundaries and leads to a more efficient reduction in computational domain. In this study, wave generation using a wave time history is used to directly simulate the physical model tests conducted by Hughes and Nadal (2009). The assumptions used within this wave generating procedure are that the high frequency energy is dissipated by the breaking waves at the embankment and the long wave components reflected from the shore propagate as non-dispersive waves according to linear shallow water wave theory; so that at the boundary linear superposition between incident and reflected waves is valid. In order to reproduce the required waves at the boundary, as well as wave height data, the model also requires the velocity components at the boundary. This was derived from the wave height data using linear theory.

With a wave overtopping model a system has to be devised to ensure that the discharge is recycled back into the flume. This ensures the conservation of mass failure to do this would result in a lowering of water level within the flume over time. To implement this in the model the depth and velocity information at the crest of the embanment is used to determined the discharge. The discharge is used as an input back into the model as a depth averaged velocity at the seaward boundary. This velocity is combined with the velocity determined for wave generation. If the instantaneous discharge is directly fed back into the wave generating boundary, it effectively generates a false wave at the boundary. To overcome this problem, whilst still maintaining a conservation of mass, a running average discharge is used to feed the seaward boundary. It was found that a running mean over a twenty second period successfully produced the required wave profiles. It will later be shown that the degree of success of the wave generating procedure is satisfactory.

The next section briefly describes the physical model laboratory study of combined discharge conducted by Hughes and Nadal (2009), a more detail description of the tests can be found in the original paper. A number of the test conducted by Hughes and Nadal were simulated with the RANS-VOF model and comparisons between various recorded and predicted parameters are made. 


\section{Experimental data}

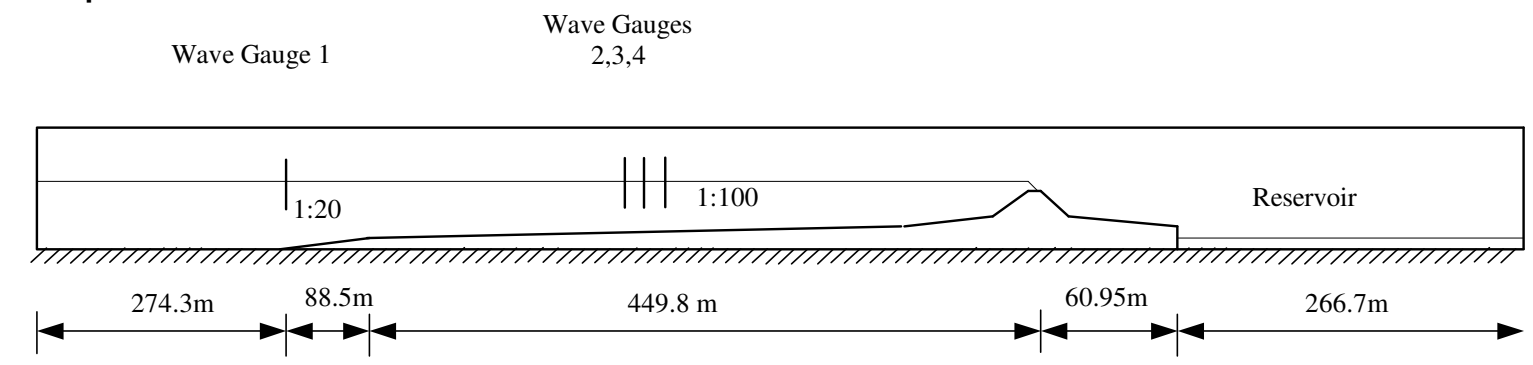

Fig. 1 General set-up of flume with the prototype embankment.

Hughes and Nadal (2009) conducted a series of physical model flume tests of combined discharge over an embankment, a brief description of the model tests is given here. The tests were conducted at a scale of 1:25. Fig. 1 shows the general flume setup and Fig. 2 shows the detail of a cross section through the embankment. Recirculation of the discharge over the crest was achieved in the physical model by pumping the water from the reservoir to near the wave generator. Adjusting the flow rate in the pump set the surge level tested in the model.

EL $15.25 \mathrm{~m}$

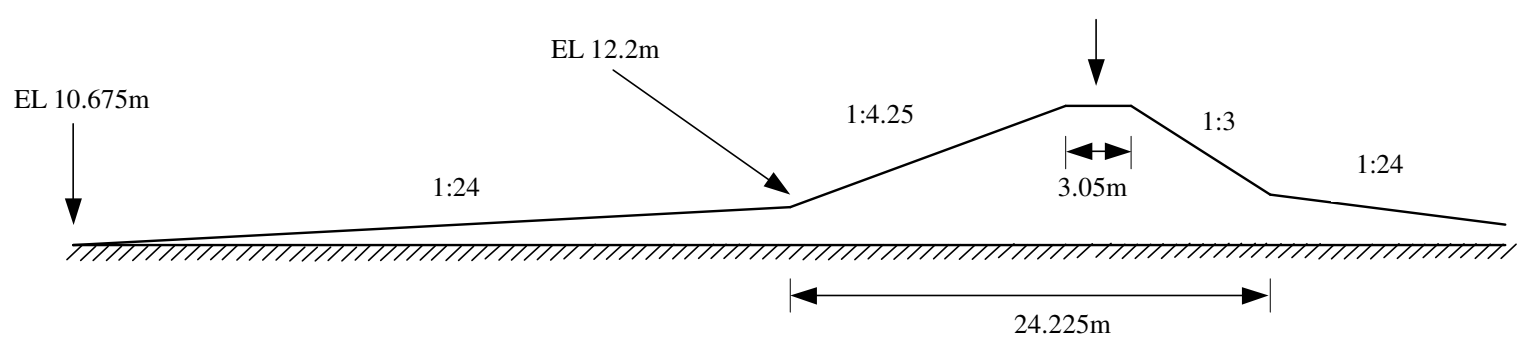

Fig. 2 Detail of the prototype embankment cross section.

The flume model used four resistance type wave gauges, one near the wave generator and a threegauge array on the 1:100 slope. Flow depth over the embankment was recorded with pressure cells. The location of the pressure cells is given in Fig. 3. The horizontal flow velocity directly above pressure gauge 2 (P2) was recorded with a Laser Doppler Velocimeter (LDV). The location of the LDV was adjusted for each test so that the velocitv was alwavs recorded at half of the flow depth.

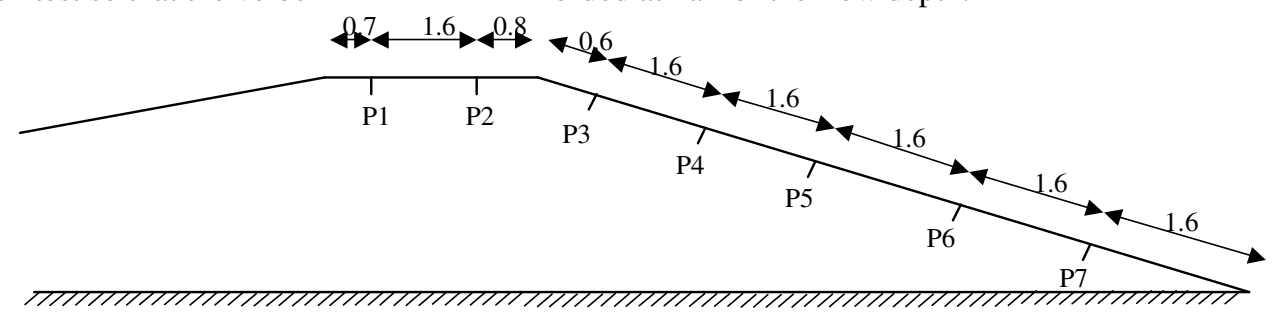

Fig. 3 Location of pressure cell on the prototype embankment, dimensions in $\mathrm{m}$.

The test programme investigated storm surge levels of $0.29,0.81$ and $1.3 \mathrm{~m}$ above the embankment crest. Each storm surge level was tested for three wave heights and three wave periods. This gave a total of 27 tests.

Wide embankments, when subjected to surge overflow, act as a broad crested weir, with flow at the crest progressing from sub critical flow near the seaward boundary to critical and then supercritical flow on the lee side. This means the flow depth on the embankment crest will vary with location across the crest. In order to determine an appropriate surge level the model was run without waves for an initial period at the start of each test. The steady discharge for this period was determined with the flow depth and velocity information at P2. The surge level was then determined from the equation for flow over a broad crested weir, Equation (2) with a Cd value of 1.0. This allowed the upstream surge level to be estimated from the measured discharge. This surge level would be more useful to designers than a depth at the weir because it 
corresponds to the surge level calculated from tide and meteorological conditions. A surge level recorded at the embankment crest would be subject to the draw down that occurs near weirs.

The pressure and velocity data for the tests were collected at $50 \mathrm{~Hz}$ and a total of 15000 data points was collected for each channel, giving an equivalent of 1500 s of prototype scale data. The first 500 data points from each test was used to determine the steady discharge conditions, with waves beginning to reach the embankment shortly after this. To determine combined discharge when the embankment was subject to waves and steady discharge the discharge average over the prototype time period 100 to 1500 s was used.

As already stated the discharge was determined at P2 with reference to the flow depth and velocity recorded at half depth. However, when the embankment was subjected to waves the water level would periodically drop below the level of the LDV. The LDV was set so that when this occurred the velocity recorded would remain at the last value recorded. This is more likely to occur on the tests with the lower surge levels. As a consequence the average discharges would be higher than expected. To determine the range of this error a second calculation was done with the LDV set to zero when the water level dropped below the laser level. These two sets of reading effectively gave the maximum range of the error. Hughes and Nadal (2009) determined that the maximum difference caused by this problem was $13 \%$ for a test at the lower surge level. On average it caused a $4 \%$ error. For tests at the highest surge level the LDV mostly remained submerged and so the problem was less apparent.

For this paper the RANS-VOF model has been used to simulate the tests conducted at the larger $1.3 \mathrm{~m}$ surge level. The table below give a list of wave conditions tested.

\begin{tabular}{|c|l|l|l|}
\hline Test Number & $\mathrm{H}_{\mathrm{m} 0}$ & $\mathrm{~T}_{\mathrm{p}}$ & $\xi_{\mathrm{p}}$ \\
\hline 1 & 0.64 & 6.07 & 2.1 \\
\hline 2 & 1.17 & 6.07 & 1.6 \\
\hline 3 & 2.3 & 6.07 & 1.2 \\
\hline 4 & 0.86 & 10.12 & 3.3 \\
\hline 5 & 1.79 & 10.12 & 2.4 \\
\hline 6 & 2.74 & 10.12 & 1.8 \\
\hline 7 & 0.74 & 14.37 & 5.0 \\
\hline 8 & 1.5 & 14.37 & 3.5 \\
\hline 9 & 2.31 & 14.37 & 2.8 \\
\hline
\end{tabular}

Table 1 Wave conditions tested and Iribarren number.

\section{Description of the numerical model}

For computational efficiency only part of the physical model flume was reproduced in the RANS-VOF model. The wave input signal for the RANS-VOF model was taken from wave gauge 2, G2, in the physical model and so the seaward boundary of the model was the G2 location. This allowed waves generated within the RANS-VOF model to be compared with those measured at G3 and G4 in the physical model.The landward boundary of the RANS-VOF model was defined as being on the 1:3 slope on the lee side of the embankment. This boundary was defined as being an open boundary, so allowing waves to exit the flume without reflection. The boundary condition used at the bottom was a rigid free slip condition, which is used when the mesh size is thicker than the viscous boundary layer and so the $k$ - $\varepsilon$ turbulence model is used. The vertical extent of the computational mesh was determined by the largest wave, so that the wave did not touch the top of the flume. Reducing the height where possible ensured computational efficiency. Fig. 4 shows the model set-up along with a snapshot of the wave surface elevation and flow field velocity vectors.

The defining criterion for the mesh size was that the mesh had to be small enough to resolve the supercritical flow on the landward side of the embankment. To achieve this a mesh size for all $1.3 \mathrm{~m}$ surge tests was $0.4 \mathrm{~m}$ in the horizontal direction and $0.1 \mathrm{~m}$ in the vertical direction. This gave a total of up to 58600 node points. The mesh size was required to adequately define the flow over the crest of the embankment and to define the waves whilst still being computationally efficient. To confirm that the results were not dependent on mesh size, a test was conducted with mesh size of $0.2 \mathrm{~m}$ in the horizontal direction and $0.05 \mathrm{~m}$ in the vertical direction, 234432 node points. Results for the more refined mesh were near identical to the coarser mesh and provided no advantage.

The time step used for all tests was $0.01 \mathrm{~s}$. The test duration of the RANS-VOF model was $250 \mathrm{~s}$. This allowed approximately 100 s of steady flow with no waves followed by 150 s of steady surge with waves. The initial period allowed the surge level in the model to be calculated by using Equation (2). The discharge in the model was also calculated at the location of P2. However, unlike the physical model that 
only recorded the velocity at half of the average depth at P2, in the RANS-VOF model the velocities are evaluated at each node allowing a depth integrated discharge to be calculated.

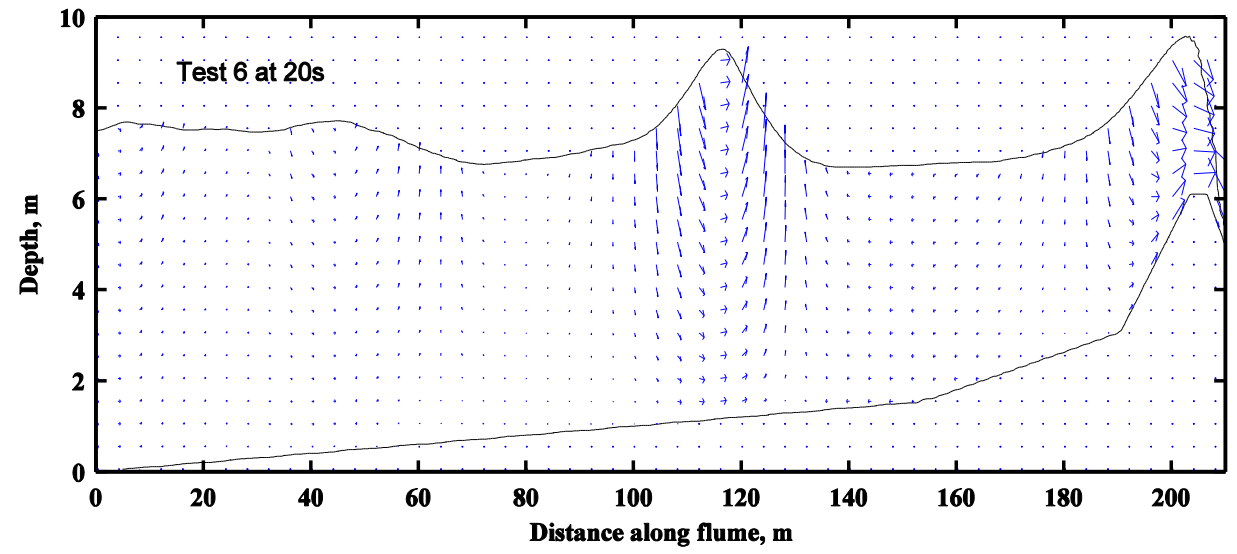

Fig. 4 A snap shot showing wave surface elevation, embankment detail and flow field velocity vectors plotted at every fifth node vertically and every tenth node horizontally.

\section{Comparison between RANS-VOF model and physical model results}

\section{Wave generation}

As already mentioned waves generated in the RANS-VOF model used the waves recorded at wave G2 in the physical model. For verification purposes it is useful to compare waves recorded at wave G4 in the physical model with those in the equivalent position in the RANS-VOF model. As the wave gauge is only $14.922 \mathrm{~m}$ away from the wave-generating boundary and little wave transformation will have occurred, this is a good test of the wave generating boundary condition. This comparison is shown in Figure 5 for a representative sample of tests. The tests shown were selected to show each of the wave periods and wave heights. There is good agreement throughout the test and demonstrates that the assumption that breaking waves dissipated high frequency energy is valid and that there is no build-up of unwanted long wave reflections.
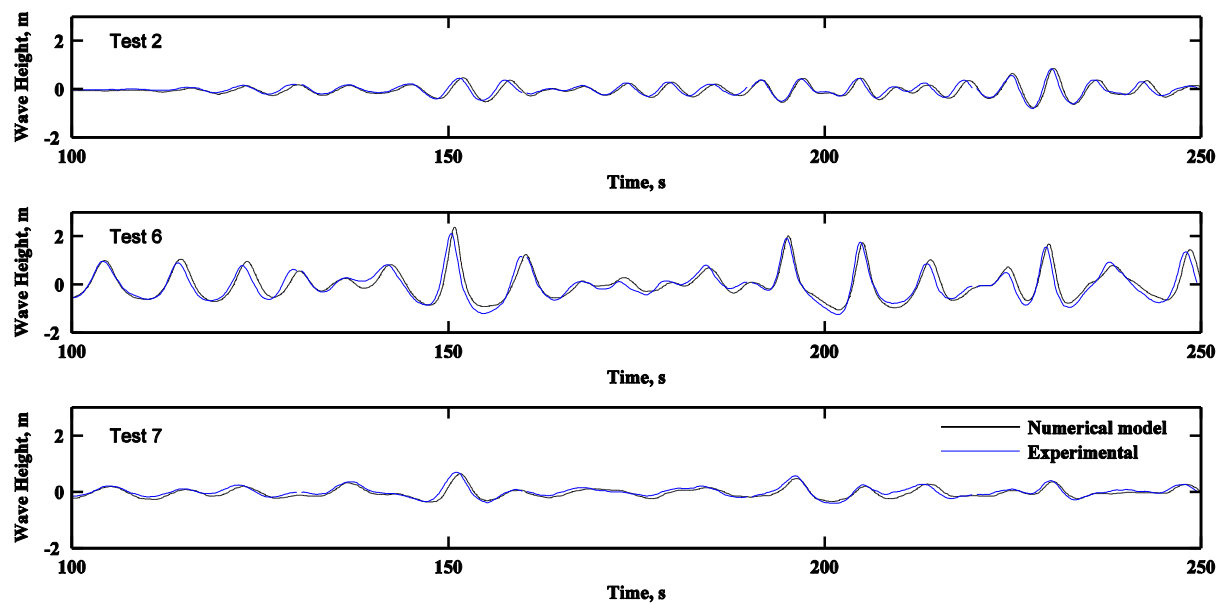

Fig. 5 Comparison of wave generated at G4.

\section{Discharge comparison}

The discharge in both the physical model and the RANS-VOF model was calculated at the crest of the embankment using the flow depth and velocity information. In the RANS-VOF model, the discharge through partially filled cells was calculated with reference to the VOF function. The calculated discharge with steady overflow and no waves (qs) and the discharge with combined wave overtopping and overflow 
(qws) were averaged over the same time period in physical model and the RANS-VOF test to ensure equivalence. The start time for the averaging period for $q_{w s}$ began when the waves had reached the embankment and were established. Table 2 gives discharge rates and the discrepancy between the laboratory and numerical models in terms of the relative error (the numerical model predicted relative to the laboratory results). It can be seen that generally the models compare well, however there is an increase in relative error for the tests with larger wave heights. The average relative error for the lower wave heights tested (Tests 1,4 , and 7) is $-0.5 \%$. At the larger wave heights (Tests 3,6 and 9) the average relative error is $+7.8 \%$.

\begin{tabular}{|c|c|c|c|c|c|c|}
\hline \multirow[t]{2}{*}{ Test } & \multicolumn{2}{|c|}{ Physical Model } & \multicolumn{2}{|c|}{ RANS-VOF } & \multirow{2}{*}{\begin{tabular}{l}
\multicolumn{1}{c}{$\mathrm{q}_{\mathrm{s}}$} \\
relative \\
error \\
$\quad(\%)$
\end{tabular}} & \multirow{2}{*}{$\begin{array}{l}\quad \mathrm{q}_{\mathrm{ws}} \\
\text { relative } \\
\text { error } \\
\quad(\%)\end{array}$} \\
\hline & $\begin{array}{c}q_{s} \\
\left(m^{3} / s / m\right)\end{array}$ & $\begin{array}{l}\mathrm{q}_{\mathrm{ws}} \\
\left(\mathrm{m}^{3} / \mathrm{s} / \mathrm{m}\right)\end{array}$ & $\begin{array}{l}\mathrm{q}_{\mathrm{s}} \\
\left(\mathrm{m}^{3} / \mathrm{s} / \mathrm{m}\right)\end{array}$ & $\begin{array}{l}q_{w s} \\
\left(\mathrm{~m}^{3} / \mathrm{s} / \mathrm{m}\right)\end{array}$ & & \\
\hline 1 & 2.53 & 2.62 & 2.56 & 2.68 & 1.27 & 2.06 \\
\hline 2 & 2.46 & 2.59 & 2.49 & 2.63 & 1.26 & 1.82 \\
\hline 3 & 2.40 & 2.72 & 2.47 & 2.89 & 2.70 & 6.55 \\
\hline 4 & 2.63 & 2.68 & 2.53 & 2.62 & -3.99 & -2.13 \\
\hline 5 & 2.53 & 2.67 & 2.53 & 2.78 & -0.24 & 4.20 \\
\hline 6 & 2.70 & 2.71 & 2.56 & 2.98 & -5.07 & 9.96 \\
\hline 7 & 2.57 & 2.66 & 2.54 & 2.63 & -0.93 & -1.43 \\
\hline 8 & 2.51 & 2.57 & 2.40 & 2.73 & -4.23 & 6.43 \\
\hline 9 & 2.53 & 2.75 & 2.50 & 2.94 & -1.30 & 6.83 \\
\hline
\end{tabular}

Table 2 Comparison of discharge rates.

In order to determine why the tests with larger wave heights record higher discharge peaks in the RANS-VOF model than the physical model it is useful to plot the time histories of discharge. These are shown below for the same sample tests.
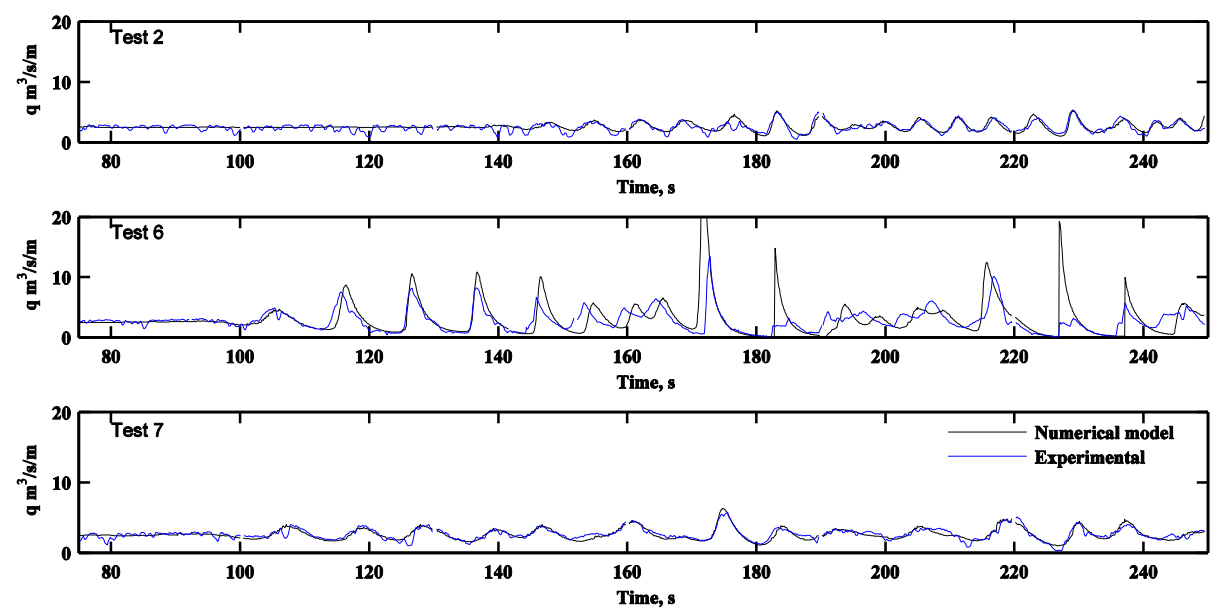

Fig. 6 Comparison of discharge at P2.

Although the general agreement is very good the RANS-VOF model has slightly larger peaks, particularly at the larger wave height (Test 6). It also shows a slight phase shift for some of the peaks and a couple of peaks showing substantial differences. This could be a result of differences in either the surge depth or velocity measurement or both. To investigate this further a comparison of time histories of surge depth and velocity in each model has been performed.

\section{Flow depth comparison}

The time histories of water depth at the embankment crest for Test 2,6 and 7 are shown in Fig. 7. Again the comparison is very good for the smaller wave heights but for some of the waves in the larger wave test (Test 6) the peaks in the RANS-VOF model are over represented. The phase shift is limited to just two of the larger peaks and the two discharge peaks at about 185 and 230s show a more favourable comparison of water depth but with the RANS-VOF model peaks still being larger than that from the laboratory. 

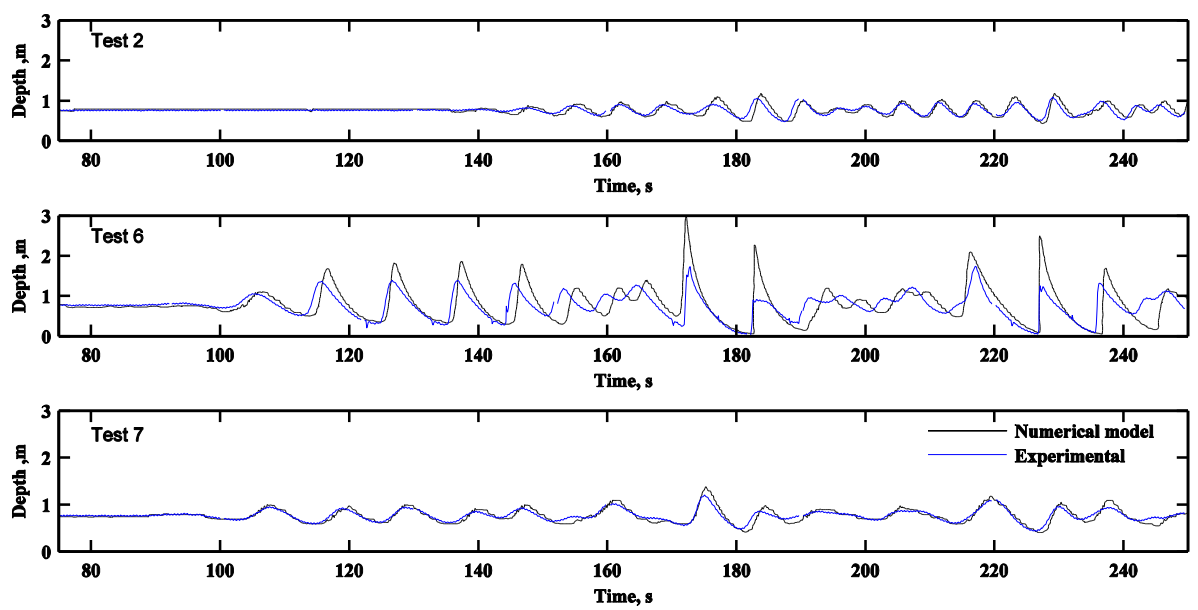

Fig. 7 Comparison of flow depth at P2.

\section{Velocity comparison}

Figure 8 shows the time histories of flow velocities at the crest of the embankment, the velocities for the RANS-VOF model are depth averaged whilst the physical model velocities are recorded at mid-depth. It is evident that the velocity time history from the physical model is quite spiky, this is particularly true of the velocities recorded during the steady surge period of Test 2 . The variation in the discharges shown for Test 2 result from the variable nature of the velocity signal for this period.

For all tests the peak velocities recorded in the physical model are generally larger than those recorded in the RANS-VOF model. In Test 6 , it can be seen that when the water level fell below the level of the LDV in the physical model the recorded velocities remained uniform during this period. This has affected the two largest velocity peaks at approximately $185 \mathrm{~s}$ and $230 \mathrm{~s}$ in the record. Each of these results has flat periods that extend onto the next peak and have significantly reduced the following peaks. These under predictions of velocities correspond to an under prediction of discharge and are the two peaks that appear as over predictions in the RANS-VOF model in Figure 6.
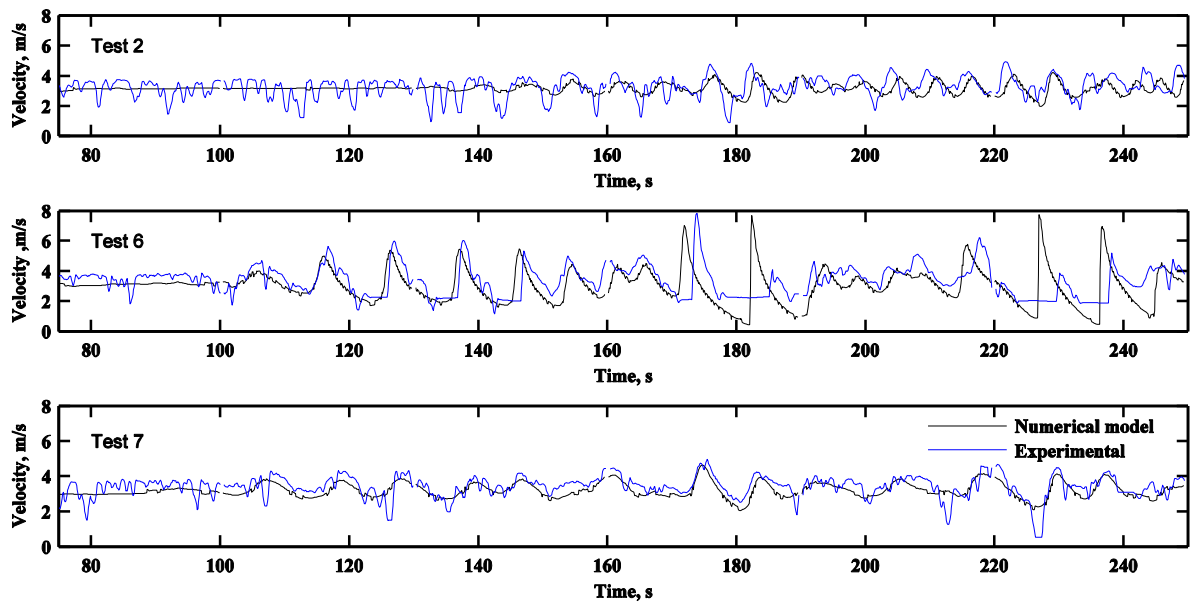

Fig. 8 Comparison of velocities under combined discharge conditions at P2. 


\section{Discussion of results}

The prediction of discharge using the RANS-VOF model is generally very good, however for larger wave heights the discrepancy between the predictions made by RANS-VOF and physical model tend to increase. These discrepancies could be due to the assumptions made within the RANS-VOF model or could be due to scale effect or modelling methodology within the physical model or possibly a combination of both. In this section the variation between the computational and physical model results are considered.

In the physical model it has been shown that the velocity record shows a time delay between the time the water level rising above the LDV and when the LDV begins to record data. This has occasionally resulted in the next peak not being recorded and subsequently the next discharge peak being underrepresented.

A comparison of flow depth at the embankment crest shows good agreement between the RANS-VOF model and physical model for all but the peaks of the largest waves. However the peaks are larger in the RANS-VOF model than in the physical model. This difference could be due to RANS-VOF model not correctly describing the flow conditions during wave peaks at the embankment crest. The free surface profile of a typical peak wave is shown in Fig. 9 and shows that, for some tests, the wave is clearly breaking at the embankment crest.

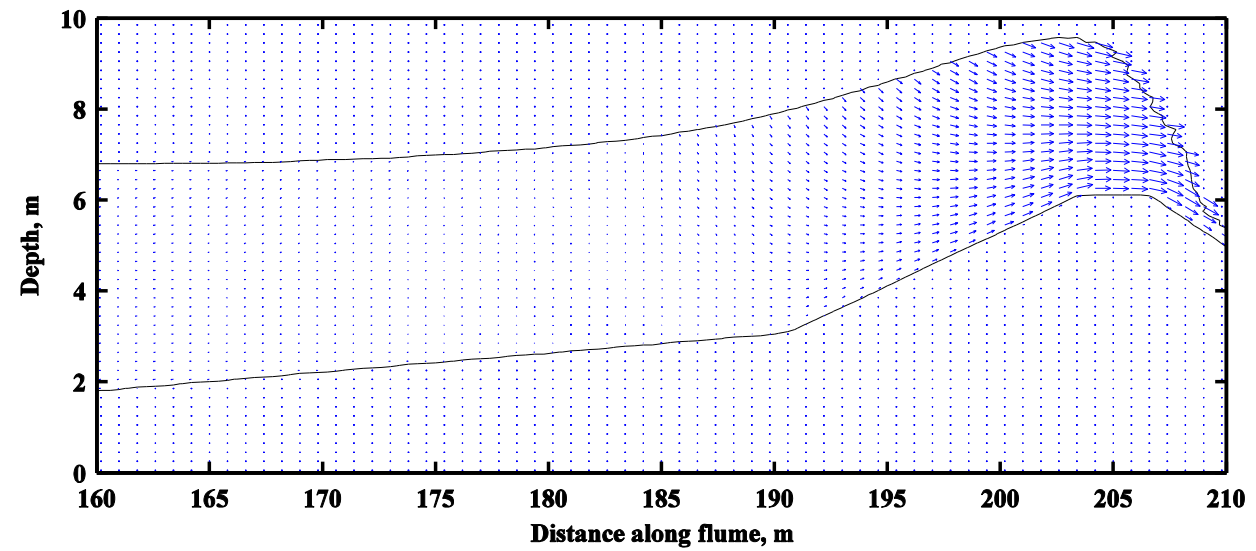

Fig. 9 Free surface profile for Test 6 at 172s showing a breaking wave and the velocity vectors plotted at alternate nodes.

Lin and Liu (1998) validated the RANS-VOF model for a cnoidal wave breaking on a sloping beach against numerical and laboratory data. Although the hydrodynamics of a wave breaking on a sloping beach will be different to a wave breaking on the top of an embankment with combined overflow, it is useful to consider how the RANS-VOF model performs near a breaking wave. In these tests a comparison was made for mean quantities such as wave elevation, velocities and turbulence at points in a breaking wave. The mean quantities were obtained by phase averaging after waves had reached a quasi-steady state. Four locations were investigated on the landward side of the breaking point, with the nearest point being about a quarter of a wavelength from the breaker point. For these tests it was found that, at the point nearest to the breaking point, the crests measured in the model were lower than the laboratory data and the velocities were higher. This is the opposite of that found in the current study. In the Lin and Liu study it was found that nearer to the breaking point turbulence intensity was overestimated and quite different to the measurements. The lower crest elevations were a result of the excessive estimated turbulence intensity. Further from the breaker point the RANS-VOF model more accurately represented the turbulence intensity and consequently the water surface elevation was also better represented. The poorer representation of the turbulence intensity near the breaker point was caused by the model not accurately predicting the initiation of turbulence in the initial stages of wave breaking where a rapidly distorted shear flow region exists. These uncertainties in the initial turbulence conditions at the initiation of breaking present difficulties in predicting the location of the breaking point. As stated above the turbulence closure model used in the RANS-VOF model describes the velocity profile in a steady, uniform, turbulent boundary layer, which is not the situation in a breaking wave.

The comparison between calculated and measured values in the current series of tests differs from the study by Lin and Liu (1998) in that it is not the phase averaged quantities being compared but the 
instantaneous measurements. Also the instantaneous measurements at P2 are at the breaking point, where the phase-averaged measurements were at about a quarter of a wavelength from the breaking point.

To determine the type of wave at the crest of the embankment the Iribarren number, $\xi$, has been calculated for each test. These values are shown in Table 1 . Where $\xi$ is less than two, indicating plunging breakers, generally a worse comparison was found for combined discharge. For tests where $\xi$ is greater than two, surging waves, the RANS-VOF model generally provided a better representation of wave overtopping discharge. This is because the turbulence regime under a wave depends on the nature of the wave and whether it is breaking. Our results indicate that the present RANS-VOF model is not fully able to reproduce the surface profile and breaking point for a plunging wave. These predictions can be affected by turbulent closure model as well as the temporal and spatial numerical scheme as suggested by Wang et al (2009).
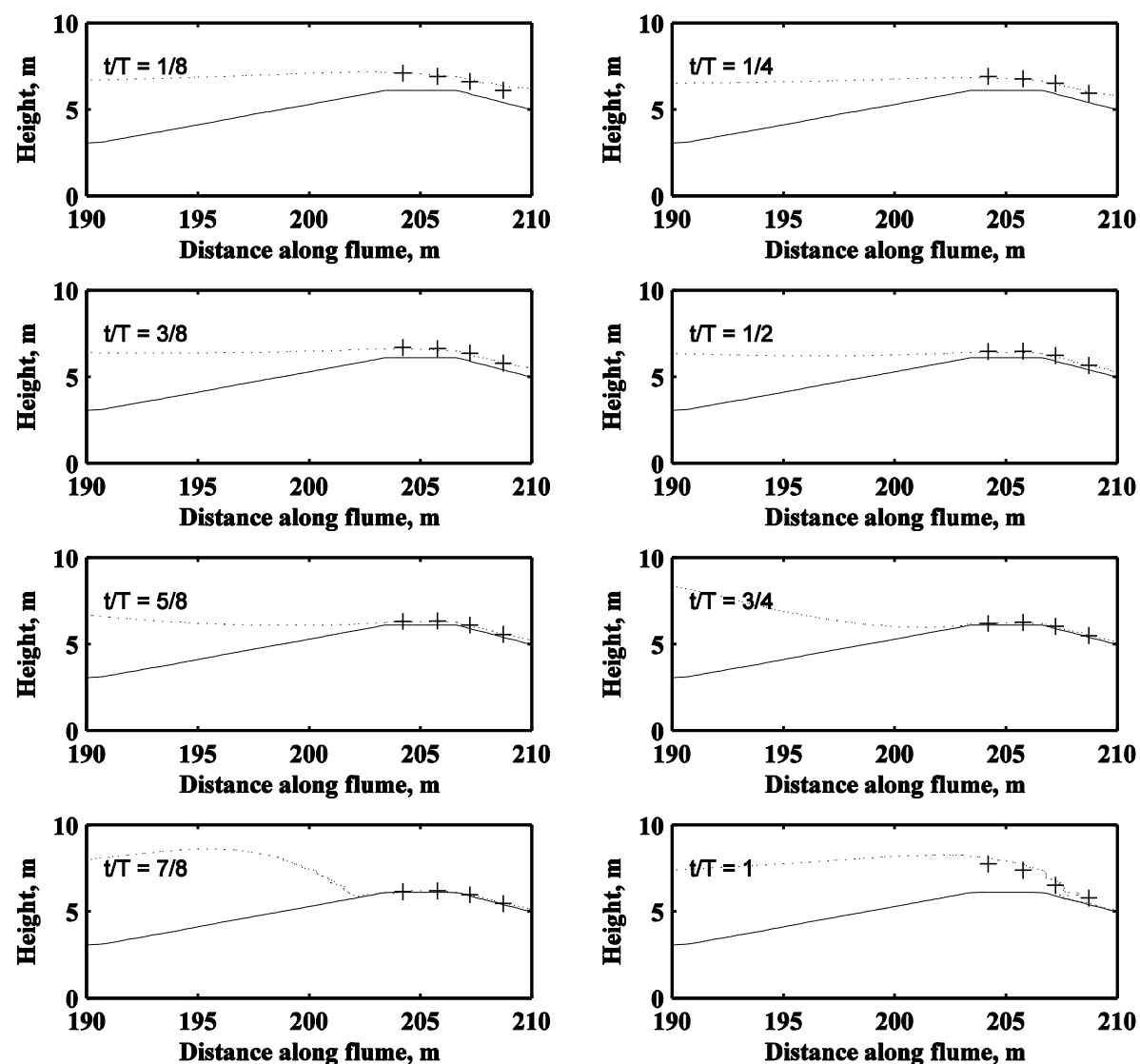

Fig. 10 Embankment profile(solid line), RANS-VOF calculated free surface (dotted line) and measured free surface at P1, P2, P3 and P4 (crosses) for Test 6.

As already discussed, Fig. 9 shows that location of the breaking point occurs at the crest of the embankment. The actual breaking point occurs near the rear edge of the crest. This is near P2, which is the point at which the velocities and depths were recorded in the physical model. This is clearly a region of great flux and small changes in the computed location of the breaker point will significantly alter the calculated depth at this point. Although it is not possible to compare discharge at locations other than P2, it is possible to compare the flow depths. The free surface profiles of measured and calculated data are shown in Fig. 10 for intervals through a breaking wave, at locations P1, P2, P3 and P4. This is for one of the larger waves in Test 6 and demonstrates that the embankment crest will dry for short periods. The figure shows good agreement between RANS-VOF results and the physical model data, however at the point when the 
wave breaks the agreement is not as good. This is in agreement with the depth time histories shown in Fig. 7, with the depths at the highest waves being over predicted in the RANS-VOF model. Figure 10 confirms that the over prediction is not localised to P2. However in the RANS-VOF model the wave is breaking very near to the location of P2 and small errors in the calculation of this location will have a large effect on the depth of flow at the breaker location.

\section{Model comparison against design formulae}

In this section the discharge calculated with the RANS-VOF model is compared with available design formulae for combined overtopping.

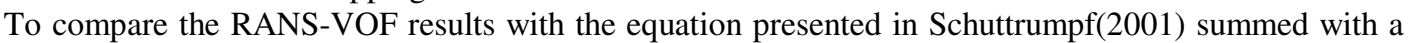
broad crested weir equation, the most appropriate weir equation must be selected. Pullen (2007) suggested Equation (4) could be used to calculate the weir discharge, which can be calculated directly from the depth of flow over the weir, this is the equivalent to the negative freeboard $R_{c}$. However, the flow over a broad crested weir can vary from sub critical to critical and then super critical so the flow depth will vary with location. Consequently the value of $q$ calculated in Equation (4) is dependent on where $R_{c}$ is recorded. For broad crested weirs it is usual to use the upstream head measured at a distance sufficiently upstream to be relatively free from the draw down in water surface elevation near the weir. In terms of water level above a seawall, this corresponds to the still water level plus the surge component. Equation (2) uses the upstream head and is based on ideal flow conditions with the value of $\mathrm{Cd}$ found from empirical formulae and is 1.0 for ideal flow. Reeve et al. (2008) used Equation (2) for comparison purposes with the value of Cd is given by Equation (3) which has a range of validity of $0.45<\mathrm{h} / \mathrm{L}<0.8$ and $0.35<\mathrm{h} /\left(\mathrm{h}+\mathrm{h}_{1}\right)<0.6$. For the tests conducted in this study $\mathrm{h} / \mathrm{L}$ have a range from 0.1 to 0.44 and $\mathrm{h} /\left(\mathrm{h}+\mathrm{h}_{1}\right)$ has a range of 0.09 to 0.30 , therefore the value of $\mathrm{Cd}$ calculated with Equation (3) will be outside the acceptable range for the formula. The approach adopted by Hughes and Nadal was to calculate the equivalent upstream head above the weir crest from the measured steady discharge at the start of each test using Equation (2) with a Cd value of 1.0. For the purposes of comparison the value of $R_{c}$ calculated from the steady discharge part of the RANS-VOF tests using the same procedure as adopted by Hughes and Nadal was used to predict dimensionless discharge for each of the design formulae. The comparison is shown in Fig. 11 and this figure is comparable with $\quad$ Figure 7 in Hughes and (2009).

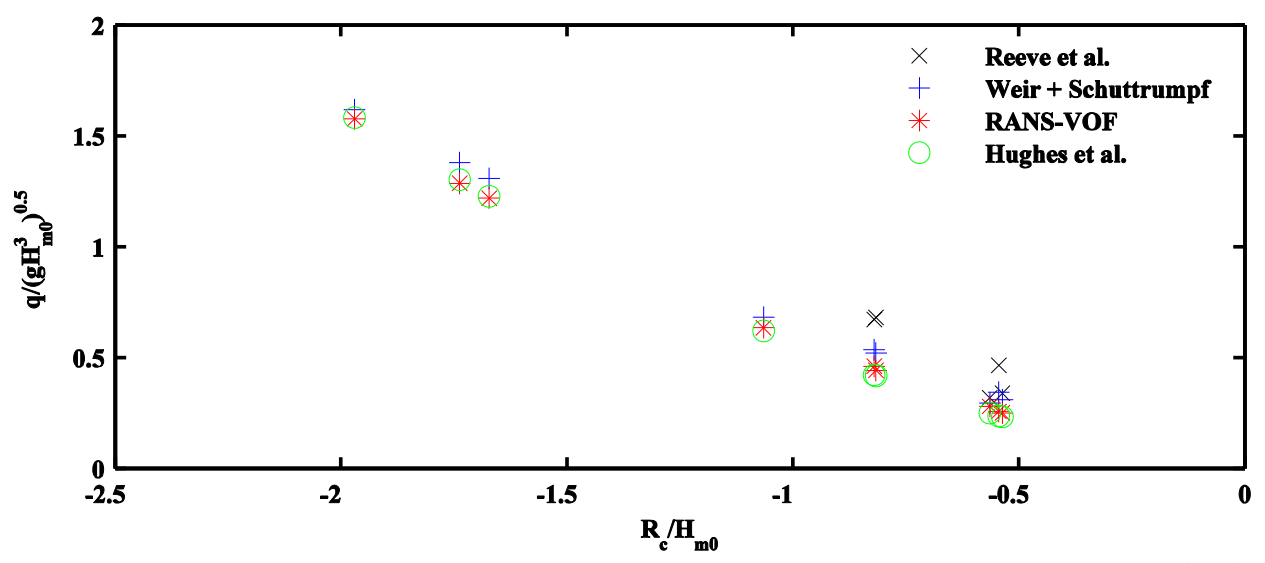

Fig. 11 Dimensionless discharge and dimensionless negative freeboard for the RANS-VOF test and calculated values based on $\mathbf{R}_{\mathrm{c}}$ calculated from Equation 2 .

The dimensionless discharge calculated with the RANS-VOF model generally compares well with that predicted by Equations (1) and (2) and Equation (6). The dimensionless discharge calculated using Equations (1) and (2) is slightly larger than that found with the RANS-VOF model and that found with Equation (6) is generally slightly less. It is noted that better agreement is found for more negative values of $R_{c} / H_{m 0}$. The range of applicability of Equation (5) is for negative freeboards in the region $0>R_{c} / H s>-1.0$, a number of the tests conducted in this series of tests were outside of this range of applicability and this data has been excluded from Fig. 11. The remaining data shows an overestimation of the dimensionless discharge when compared with the other results. 
A problem with this analysis is that the steady discharge at the start of the test has been used to calculate $R_{c}$ rather than a direct measurement. Also using Equation (2) for this calculation with a value of $\mathrm{Cd}$ set to 1.0 assumes ideal flow. This method of calculating $\mathrm{R}_{\mathrm{c}}$ values may well produce different values to $\mathrm{R}_{\mathrm{c}}$ determined from meteorological and surge calculations.

ISO 3846:2008 is the international standard for flow over a broad crested weirs and recommends that the upstream head readings should be recorded between 3 and 4 times the maximum level upstream from the upstream face of the weir. This allows a measurement of head which is a sufficient distance upstream to avoid the draw down near the weir and is close enough to the weir for the energy loss between the measurement location and the weir to be negligible. The equation given in the standard is equivalent to Equation (2), with tables and graphs that allow $\mathrm{Cd}$ to be evaluated, with $\mathrm{Cd}$ being dependent on the ratios of the surge level to crest width and surge level to height of weir. To determine the value of $\mathrm{R}_{\mathrm{c}}$ for the RANSVOF tests in accordance with ISO 3846:2008 the average depth was determined during the steady surge part of the test for the period 30-80 seconds at a location near 3.5 times the nominal surge depth from the seaward edge of the embankment. The value of $\mathrm{R}_{\mathrm{c}}$ found using this method was on average $6.0 \%$ less that using the steady discharge and Equation (2) to calculate $\mathrm{R}_{\mathrm{c}}$.

The geometry of the broad crested weir for which Equation (2) is applicable is a rectangular weir where the upstream face forms a sharp right angle corner at its intersection with the crest. The embankment used in this study is significantly different to this design and this difference is a likely source of error. The ISO 3846:2008 states that if this edge is slightly rounded the discharge coefficient may increase significantly. For the embankment used in this study the upstream face has a 1:4.25 slope which is likely to increase discharge in a similar way to having a rounded edge. To demonstrate this the values of $R_{c}$ determined from the RANS-VOF results was used to calculate the discharge over the embankment using the Equation (2) and values of $\mathrm{Cd}$ given in ISO 3846:2008. This gave an average discharge that was $21 \%$ lower than the RANS-VOF measured discharge. The higher discharge found with the RANS-VOF model is due to the upstream face of the embankment not being perpendicular to the crest. When a non-standard broad crested weir is used in the field a calibration exercise is usually carried out either in the field or a scale model study is used to determine the characteristics of the weir. As no discharge characteristics exist for this type of weir the characteristics could be derived from the physical model study data, unfortunately the depth of flow information at the specified location is not available. However this information is available for all the combined overtopping tests conducted with the RANS-VOF model. To determine the weir characteristics a graph of measured values of $\mathrm{q}_{\mathrm{ws}}$ and $\mathrm{R}_{\mathrm{c}}{ }^{3 / 2}$ is given in Figure 12. The data is well correlated and the linear regression line has a coefficient of determination, $r^{2}$ of 0.9987 . The equation of the regression line is Equation (2) with the value of Cd calculated to be 1.126 .

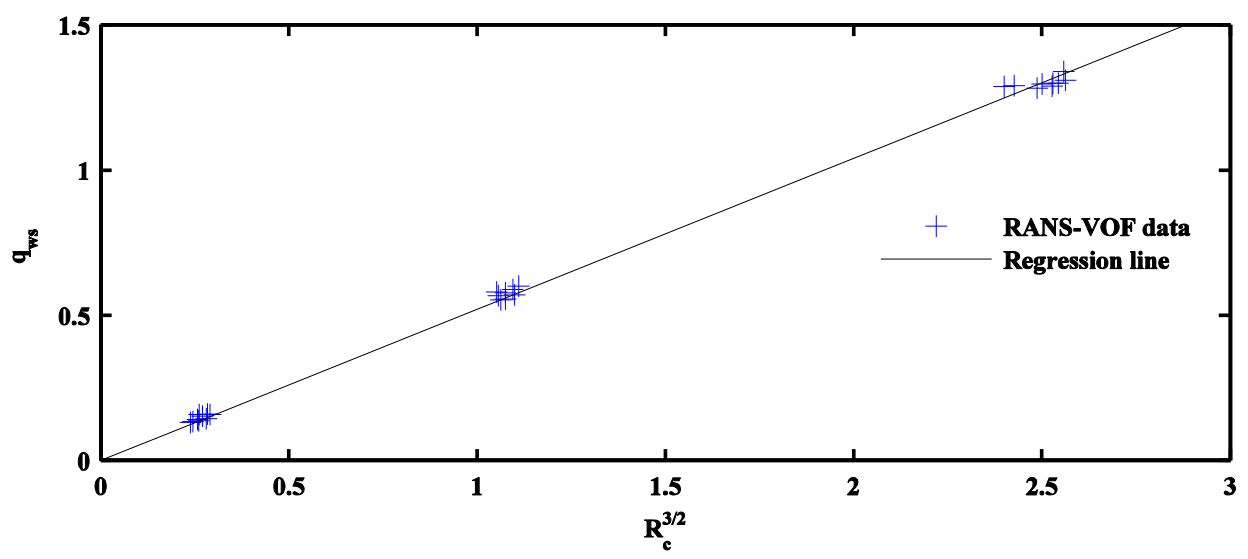

Fig. 12 Embankment steady discharge, $q_{w s}$ and $R c$ calculated with the RANS-VOF model discharge, measured in accordance with ISO 3846.

Equation (5) and (6) were used to recalculate the combined overtopping discharge over the embankment with $R_{c}$ measured in accordance with ISO 3846:2008. The combined overtopping discharge was also calculated using Schuttrumpf (2001) combined with Equation (2) with the value of Cd of 1.126. Figure 13 shows the dimensionless discharge and dimensionless freeboard for these equations along with the RANS-VOF measured values. 
Comparing Fig. 11 and Fig 13 shows that the dimensionless discharge is sensitive to the method of evaluating $\mathrm{R}_{\mathrm{c}}$. Although the dimensionless discharge calculated with the RANS-VOF model has not changed, the measured value of $R_{c}$ has reduced. This caused the RANS-VOF data points on Figure 13 to move the right. The dimensionless discharge calculated from Hughes et al., Equation (6), gives lower values than recorded with the RANS-VOF model. This is because using a value of $R_{c}$ measured in this way gives on average a $6.0 \%$ lower value for $R_{c}$. As the only parameters in Equation (6) are $R_{c}$ and $H_{m 0}$, and $H_{m 0}$ remains the same, a lower value of $R_{c}$ results in a lower dimensionless discharge. Similarly as $R_{c}$ is the only parameter to change within Equation (5) gives a lower dimensionless discharge. Although the wave component of the overtopping discharge calculated with Equation (1) has remained the same, the weir flow component calculated with Equation (2) has increased significantly. This has increased the combined total and given a combined total marginally above the RANS-VOF results. Overall the VANS-VOF results fall somewhere between the results expected from the equations provided by Reeve et al. and Hughes and Nadal and are marginally lower than the dimensionless discharge found by combining the modified weir equation and the equation provided by Schuttrumpf.

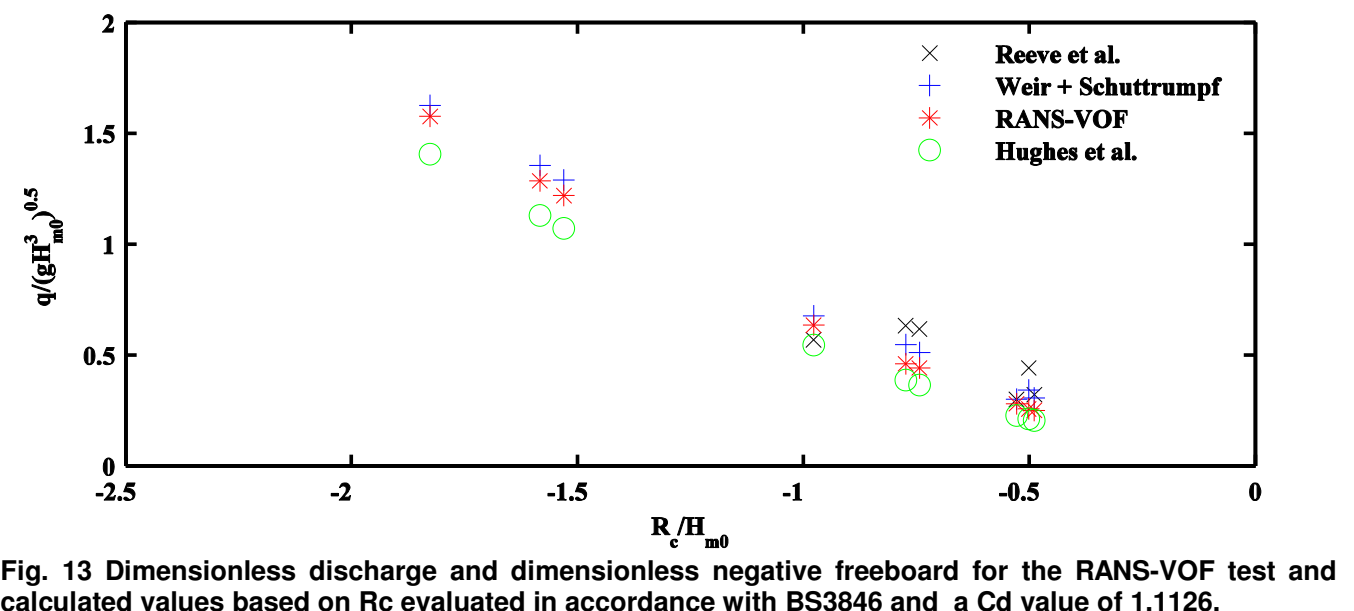

Perhaps one of the key differences between the combined wave overtopping study reported by Reeve et al. (2008) and the other studies on combined wave overtopping is the model set up. Reeve el al. used a sloping foreshore retained by a thin wall of approximately $0.5 \mathrm{~m}$ thickness. The crest of this wall would act more like a thin plate weir than a broad crested weir. The discharge over a thin wall weir is given by Douglas (1979) as;

$$
q=\frac{2}{3} B \sqrt{(2 g)} h^{3 / 2}
$$

A comparison between Equation (7) and Equation (2) shows that a thin wall would be expected to show an increase in measured discharge. This may explain why the dimensionless discharge predicted by Equation (5) is greater than recorded in the current study.

It should also be noted that as the ratio $R_{c} / H_{m 0}$ increases, i.e. as the wave height reduces, the discharge prediction should tend towards that predicted by the equation for broad crested weir. Clearly this will be true for Schuttrumpf combined with the weir equation, but it is also true for both the RANS-VOF model results but Figure 13 show this is less so for the formula derived by Hughes and Nadal.

\section{Conclusion}

The tests conducted as part of the study have demonstrated that the RANS-VOF model is able to successfully predict, on a wave-by-wave basis, wave overtopping discharge of seawalls with negative freeboards. It was found that for smaller and mid sized waves the model provided good predictions of discharge when compared with that measured in a physical model study. For larger waves the RANS-VOF model over predicted the overtopping discharge by on average $8 \%$. This is caused by a poorer representation of turbulence intensity at the breaker point leading to small errors in calculating the location the breaker point. This causes errors in the depth of flow and calculated discharge.

Much of the difference between the RANS-VOF and physical model discharges were as a result of differences in the recorded velocities. The RANS-VOF model used a depth-averaged velocity whilst a mid- 
depth velocity was recorded in the physical model, which then had to infer the velocity when the water level dropped below the ADV. On occasion the ADV did not respond immediately when the water level had increased beyond mid-depth, causing the velocity from some waves to be missed. To overcome uncertainties, there is a continued need for more physical model tests with depth integrated velocity information.

For comparative purposes, the flow depth over the seawall has been determined from steady overflow conditions using equation (2), which is the equation for discharge over a broad crested weir. However this equation assumes ideal flow and a rectangular weir configuration, a better estimate of flow depth would be found using a value of $C_{d}$ determined for real flow.

In this study a comparison was made between the output from the RANS-VOF model and existing design formulae for combined discharge over embankments. It was found that very good agreement exists between the RANS-VOF output and Equations (1) and (2) and Equation (6). Equation (1) and (2) predict slightly higher discharge than the RANS-VOF model and Equation (6) predict very marginally lower. Some of the tests conducted for this paper were outside the range of applicability of Equation (5). Those tests within the range showed that Equation (5) predicted higher discharge rates. This can be accounted for by differences in the embankment shape used in the model by Reeve et al.

The design equations considered in this paper for combined discharge are based on studies for embankments of simple design and for a limited range of slopes. For a fuller understanding a range of different design configuration needs to be investigated. Within the constraints noted earlier, the validated model is a useful and efficient design tool which can be used to investigate different embankment and sea wall design variations such as the slope of the seaward and lee face and berm configurations.

This paper has investigated the capability of the RANS-VOF model in simulating the combined storm wave and surge overtopping at a $1.3 \mathrm{~m}$ negative freeboard. The RANS-VOF model is currently being used to investigate the 0.29 and $0.81 \mathrm{~m}$ negative freeboard situations.

\section{LIST OF SYMBOLS}

b Weir crest width [m]

$\mathrm{C}_{\mathrm{d}}$ Coefficient [-]

$\mathrm{g}$ acceleration due to gravity $\left[\mathrm{m}^{2} / \mathrm{s}\right]$

$\mathrm{h} \quad$ Upstream depth of flow above weir $[\mathrm{m}]$

$\mathrm{h}_{1} \quad$ Water depth to crest of weir [m]

$\mathrm{H}_{\mathrm{m} 0}$ Mean energy wave height [m]

$\mathrm{H}_{\mathrm{s}} \quad$ Significant Wave Height $[\mathrm{m}]$

$\mathrm{k}$ turbulent kinetic energy [Nm]

L Weir crest length [m]

q Overtopping discharge $\left[\mathrm{m}^{3} / \mathrm{s}\right]$

$\mathrm{R}$ Dimensionless Freeboard [-] $R=R_{c} /\left(H_{s} \xi_{p}\right)$

$\mathrm{R}_{\mathrm{c}} \quad$ Crest Freeboard [m]

$\alpha \quad$ Sea wall slope angle $\left[{ }^{\circ}\right]$

$\varepsilon \quad$ turbulence dissipation $[\mathrm{Nm}]$

$\xi_{m-1,0}$ Surf similarity parameter (Iribarren number) defined as $\xi_{m-1,0}=\frac{\tan \alpha}{\sqrt{H_{m 0 /} L_{o m-1,0}}}$

$\xi_{p}$ Surf similarity parameter (Iribarren number) defined as $\xi_{p}=\frac{\tan \alpha}{\sqrt{H_{s /} L_{p}}}$

Other symbols are defined in the text. 


\section{ACKNOWLEDGEMENTS}

We wish to thank Professor Pengzhi Lin of Sichuan University, China for providing the original version of the RANS-VOF model and Dr Alec Torres Freyermuth for providing the modified version of the wave generator subroutine. We also wish to thank Professor Steven Hughes of the US Army Corps of Engineers for providing the data from the Levee overtopping study. David Jones acknowledges the support of a scholarship provided by Britannia Royal Naval College and Plymouth University. Dr Qingping Zou and Prof Dominic Reeve acknowledge support from the Flood Risk from Extreme Events (FREE) Programme of the UK Natural Environmental Research Council (NERC) (NE/E0002129/1), and the Flood Risk Management Research Consortium (GR/576304/01).

\section{REFERENCES}

Ackers,P., White, W. R., Perkins, J. A., and Harrison, A. J. M. 1978. Weirs and Flumes for flow Measurement, Wiley, Chichester.

Chadwick, A., Morfett, J., 1998. Hydraulics in Civil and Environmental Engineering Second Edition. E $\&$ FN SPON, London.

Chorin, A.J., 1968. Numerical solution of the Navier-Stokes equations.

Mathematics and Computation 22, 745-762.

Hirt, C. W. \& Nichols, B. D. 1981. Volume of fluid (VOF) method for dynamics of free boundaries. J. Comput. Phys. 39, 201-225.

Hu, K., Mingham, C.G., Causon, D.M., 2000. Numerical simulation of wave overtopping of coastal structure using the non-linear shallow water equation. Coastal Engineering 41, 433-465.

Hughes, S.A., Nadal, N.C., 2009. Laboratory study of combined wave overtopping and storm surge overf low of a levee. Coastal Engineering 56, 244-259.

Kobayashi, N., Wurjanto, A., 1989. Wave Overtopping on Coastal Structures. J. Waterway, Port, Coastal, and Ocean Engineering 115 (2), 235-251.

Kothe, D.B., Mjolsness, R.C., Torrey, M.D., 1991. RIPPLE: a computer program for incompressible flows with free surfaces. Report LA-12007-MS, Los Alamos Scientific Report, Los Alamos, NM, USA

Lin, P., Liu, P.L.-F., 1998. A numerical study of breaking waves in the surf zone. Journal of Fluid Mechanics 359, 239-264.

Lin, P., Liu, P.L.-F., 1999. Internal wave-maker for Navier-Stokes equations models. Waterway, Port, Coastal, and Ocean Engineering 125 (4), 207-215.

Lv, X., Zou, Q., Reeve, D., 2009. A Hybrid LS and VOF Method for 3-D Simulation of Wave Breaking and Overtopping. Intl. J. Offshore and Polar Engineering Vol. 4 No. 4, 1-9.

Nielsen, P., 1992. Coastal Bottom Boundary Layers and Sediment Transport. Advanced Series on Ocean Engineering Volume 4, World Scientific, London.

Pullen, T., Allsop, N.W.H., Bruce, T., Kortenhaus, A., Schüttrumpf, H., van der Meer, J.W., 2007. EurOtop: Wave overtopping of sea defences and related structures: Assessment Manual. www.overtoppingmanual.com.

Reeve, D.E., Soliman, A., Lin, P.Z., 2008. Numerical study of combined overflow and wave overtopping over a smooth impermeable seawall. Coastal Engineering 55, 155-166.

Schüttrumpf, H., 2001. Wellenüberlaufströmung bei Seedeichen - Experimentelle und Theoretische Untersuchungen. PhD-Thesis,

Shih, T.-H., Zhu, J., Lumley, J. L. 1996. Calculation of wall-bounded complex flows and free shear flows. Intl. J. Numer. Meth. Fluids 23, 1133-1144..

Torres-Freyermuth, A. 2007. Estudio de la Hidrodin’amica de la Zona de Rompientes mediante ecuaciones tipo RANS, PhD-Thesis, Cantabria, Spain

Wang, Z., Zou, Q., Reeve, D., 2009. Simulation of spilling breaking waves using a two phase CFD model. Computers \& Fluids 38, 1995-2005. 